\title{
It's not just FaceTime: core competencies for the Medical Virtualist
}

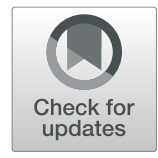

\author{
Rahul Sharma', Sapir Nachum², Karina W. Davidson ${ }^{3}$ and Michael Nochomovitz ${ }^{2 *}$
}

\begin{abstract}
New applications for virtual healthcare have resulted in an expansion of medical care beyond traditional healthcare settings. However, the rapid development of telemedicine as a field has resulted in poor standardization of the care provided through this new medium. The authors outline core competencies to be used in developing training programs for practicing physicians, medical students, and other clinicians using telemedicine as a medium for providing patient care. These competencies aim to provide a framework for defining a standard of care in telemedicine and the ultimate development of a certification in the field.
\end{abstract}

Keywords: Telemedicine, Education, Certification, Competencies

\section{Background}

The exponential growth in the use of digital devices and digital-savvy patients' demand for convenience and cost savings is driving the adoption of and demand for virtual health ahead of the maturation of training and standards. Core competencies and curricula for medical virtualism have evolved from early adopters, but have been based on experiential learning. It is incumbent on those at the edge of new technologies and services to share their experiences to advance a new field. New use cases, guidelines, and expectations are being learned in real time with more experience across specialties. Physicians and other healthcare providers with the most experience are sharing their knowledge at national meetings, mini-courses, and in publications, both peer-reviewed and in the lay press. There is a similarity with the evolution of other new disciplines like geriatrics and critical care that now have their own curricula that follow training in internal medicine. Now is the time to launch medical virtualism accreditation. We recommend a formal investigation into the core competencies needed, the innovative education training and delivery systems to be used, and the learners who need this formal recognition of their competency. We propose the competencies in this document as the basis for national discussion

\footnotetext{
* Correspondence: MIn2001@med.cornell.edu

Weill Cornell Medicine, New York, NY, USA

Full list of author information is available at the end of the article
}

and look to hold a summit on the topic based on academic medicine and industry partners.

Virtual health, telehealth, or telemedicine has only recently entered the mainstream of medical practice, care delivery, and medical literature, with an explosion of recently presented concepts, use cases, and models of care $[1,2]$. This evolving practice broadly includes digital communication by clinicians, supported by homecare, emergency services, and remote monitoring. The field has shifted from focusing on minor medical illness to harnessing the technology for management of chronic and more complex conditions, particularly with regard to global payment models. Virtual health is now incorporated into the key strategic plans for most major medical centers, physician organizations, payers, and healthcare providers, with initiatives often originating in or led by emergency departments [3].

The assumption that everyday lifestyle technologies, such as FaceTime ${ }^{\circ}$, can prepare physicians and healthcare providers for virtual care is fallacious. The diversity of platforms and providers has led to documented inconsistencies in the care provided via virtual health services [4]. The maturation of virtual health as a discipline requires the standardization of core competencies for clinicians, as this new paradigm goes far beyond replacing a traditional clinician encounter and ushers in a new generation of medical practice. We have developed a curriculum including both didactic and simulation components based on our own experience and subsequently introduced a telemedicine elective for medical students. We will now include Virtual 


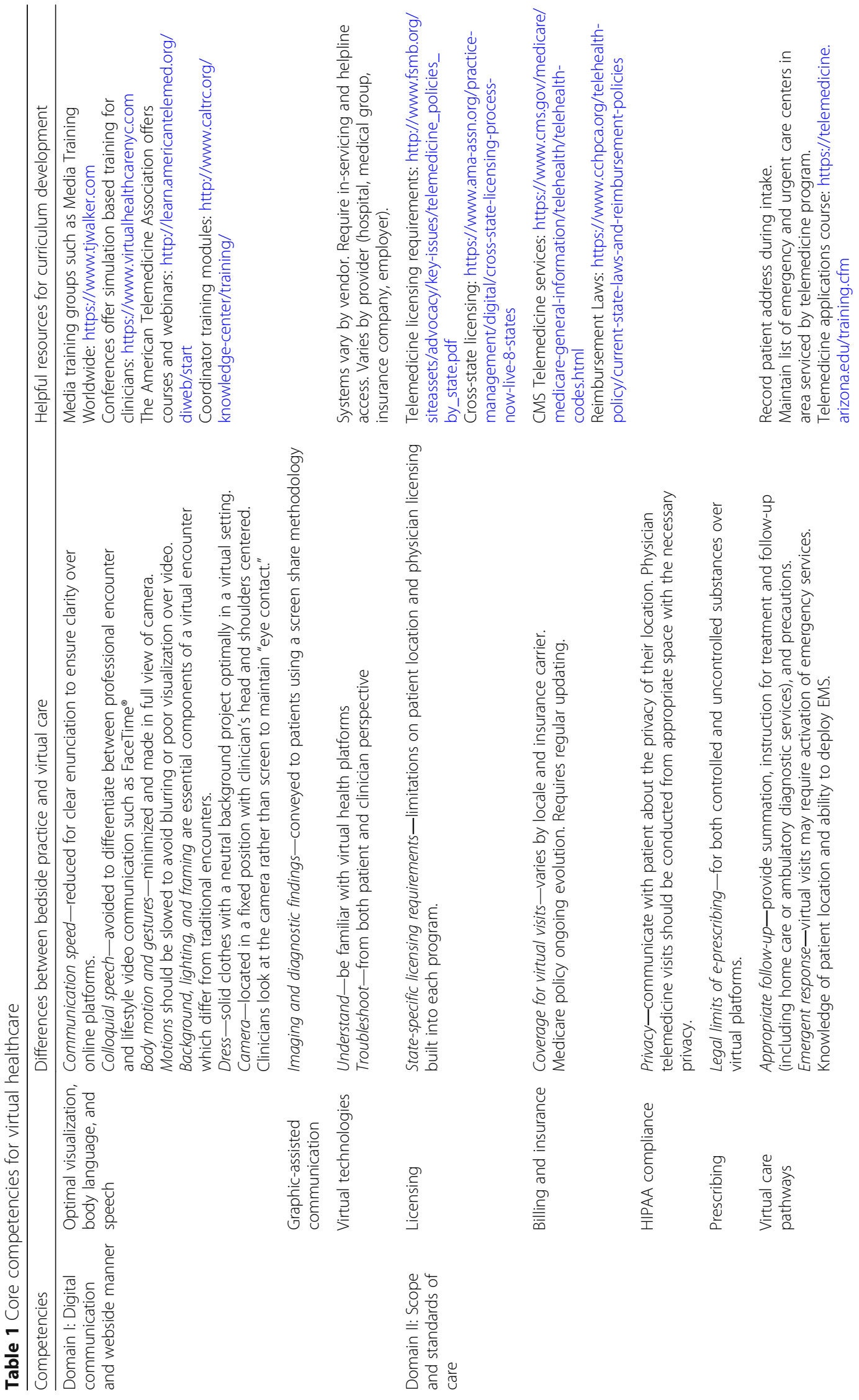




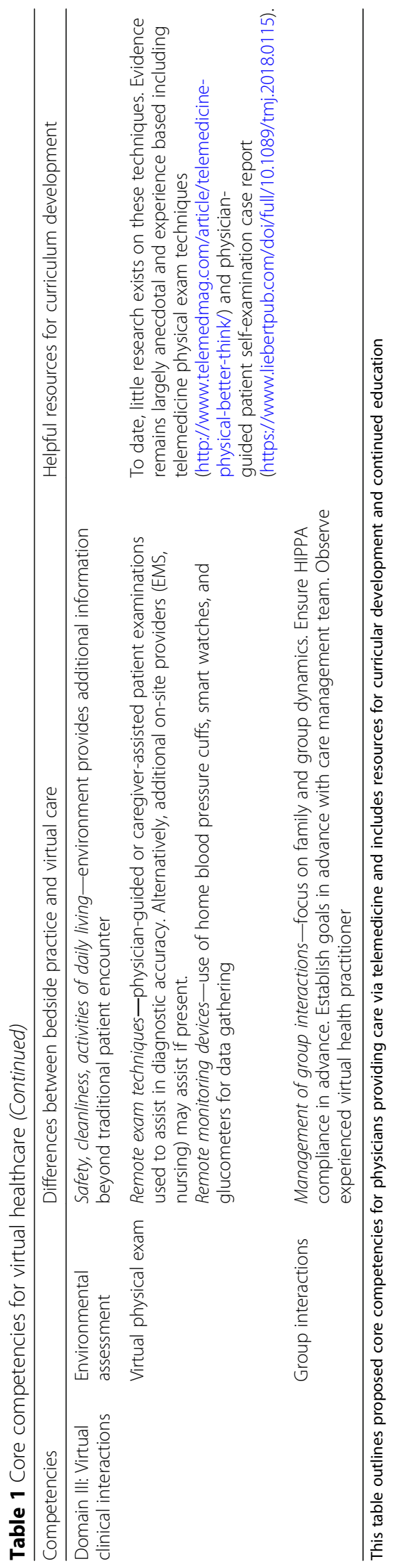


Healthcare as part of the required curriculum for all incoming medical students. We anticipate that these competencies will serve as a framework for certification in the field of virtual care as an evolving discipline integrated into the care continuum.

\section{Main text}

Licensed medical professionals are trained for the conventional practice of medicine. However, virtual healthcare adds new layers of complexity requiring competencies beyond those currently expected of all physicians [5]. A number of organizations in the public and private sector appear to be structuring their own content focused on the specific needs of their clinical programs [6]. We propose a standardization of the training for telemedicine providers and have developed a set of core competencies divided into three domains (Table 1). We expect that clinicians planning on practicing substantially as medical virtualists will need to demonstrate a set of competencies through written and simulated scenarios.

\section{Conclusions and next steps}

What is the optimal pathway to accomplish consensus on core competencies for medical virtualism? In other practice areas, we have followed various leisurely pathways. Typically, groups of practitioners and experts start to call for standards in an area. Consensus grows that there is need for additional, standardized training. Those who already have been practicing in the specific area are consulted, and consensus coalesces around the need for formally recognized competencies. Frequently, professional societies are formed, and they start to generate consensus papers on optimal training and training modules.

Nearly 2 years ago, the American Medical Association encouraged the accrediting bodies for both undergraduate and graduate medical education to include core competencies for telemedicine in their programs [7]. It is time to accelerate this timeline. How shall we ensure that medical virtualist core competencies follow the most efficient, transparent, and equitable path to training and dissemination for the many physicians and healthcare providers who will practice this way, today? Ideally, an independent, highly respected, national, non-governmental institution would convene a roundtable on medical virtualism, and do so expeditiously. The invitees should include experts from a variety of disciplines, such as biomedical informatics, ethics, medical education, as well as the medical specialties already using this approach and the accrediting organizations involved in training our future and current physician workforces. Topics to be considered are not only which core competencies to include, but how to test for competence, how to minimize harms and unintended consequences that could result from this new medical practice, and how to assess quality in this area. The white paper resulting from this type of open and national dialogue could then be posted for public comment, and demonstration training projects conducted. There likely will need to be a professional society to ensure ongoing dialogue and increasing sophistication in the type, quality, and domains of medical practice that can and should be delivered virtually.

Every passing year sees more use cases of virtual care described-the once sporadic use of the virtual medium by organizations and their clinicians is becoming ubiquitous [8]. This movement of the practice of medicine into a new sphere of virtual care will require a large cohort of clinicians to practice as medical virtualists on a fulltime basis or be acquainted with the medium and qualified to practice for periodic use. A structured training and certification program for current practitioners and all medical students is an imperative to ensure high-quality virtual care.

\section{Acknowledgements}

We thank the Emergency Medicine Telehealth Leadership Team. We also recognize Jane Torres, MS, and Charles L. Bardes, MD, Weill Cornell Medicine, for providing input on the manuscript, none of whom were compensated for their help.

\section{Funding}

Not applicable.

\section{Availability of data and materials \\ Not applicable.}

Authors' contributions

All authors contributed to the writing of and approved the final manuscript.

Ethics approval and consent to participate

Not applicable.

Consent for publication

Not applicable.

\section{Competing interests}

The authors declare that they have no competing interests.

\section{Publisher's Note}

Springer Nature remains neutral with regard to jurisdictional claims in published maps and institutional affiliations.

\section{Author details}

${ }^{1}$ NewYork-Presbyterian-Weill Cornell Medicine, New York, NY, USA. ${ }^{2}$ Weill Cornell Medicine, New York, NY, USA. ${ }^{3}$ Northwell Health, New York, NY, USA.

Received: 22 January 2019 Accepted: 28 February 2019

Published online: 12 March 2019

References

1. Nochomovitz M, Sharma R. Is it time for a new medical specialty?: The medical virtualist. JAMA. 2018;319(5):437-8.

2. Tuckson RV, Edmunds M, Hodgkins ML. Telehealth. N Engl J Med. 2017; 377(16):1585-92.

3. Spitzer J. Telehealth grows up: 5 key trends in hospital-based telehealth programs. 2018. Available from: https://www.beckershospitalreview.com/ telehealth/telehealth-grows-up-5-key-trends-in-hospital-based-telehealthprograms.html.

4. Schoenfeld AJ, Davies JM, Marafino BJ, Dean M, DeJong C, Bardach NS, et al. Variation in quality of urgent health care provided during commercial virtual visits. JAMA Intern Med. 2016;176(5):635-42. 
5. DeJong C, Lucey CR, Dudley R. Incorporating a new technology while doing no harm, virtually. JAMA. 2015;314(22):2351-2.

6. Telehealth Facilitator Certificate - Philadelphia University + Thomas Jefferson University. 2018. Available from: https://www.jefferson.edu/university/ emerging-health-professions/programs/telehealth-facilitator-certificate.html. Accessed 19 Nov 2018.

7. Reports of the Council on Medical Education. AMA; 2016. https://www.amaassn.org/sites/ama-assn.org/files/corp/media-browser/public/about-ama/ councils/Council\%20Reports/council-on-medical-education/a16-cme-reportsv2.pdf. Accessed 26 Oct 2018.

8. Barnett ML, Ray KN, Souza J, Mehrotra A. Trends in telemedicine use in a large commercially insured population, 2005-2017. JAMA. 2018;320(20):2147-9.

Ready to submit your research? Choose BMC and benefit from:

- fast, convenient online submission

- thorough peer review by experienced researchers in your field

- rapid publication on acceptance

- support for research data, including large and complex data types

- gold Open Access which fosters wider collaboration and increased citations

- maximum visibility for your research: over $100 \mathrm{M}$ website views per year

At BMC, research is always in progress.

Learn more biomedcentral.com/submissions 